\title{
The Innate Immunity in Bovine Mastitis: The Role of Pattern-Recognition Receptors
}

\author{
${ }^{1,2}$ Fernando Nogueira de Souza, \\ ${ }^{3}$ Eduardo Milton Ramos Sanchez, ${ }^{1}$ Marcos Bryan Heinemann, \\ ${ }^{4}$ Magnus Ake Gidlund, ${ }^{3}$ Luiza de Campos Reis, ${ }^{5}$ Maiara Garcia Blagitz, \\ ${ }^{6}$ Alice Maria Melville Paiva Della Libera and ${ }^{2}$ Monica Maria Oliveira Pinho Cerqueira
}

\author{
${ }^{1}$ Departament of Preventive Veterinary Medicine, \\ ${ }^{2}$ Departament of Technology and Inspection of Animal Products, \\ Veterinary School, Federal University of Minas Gerais, Belo Horizonte, Brazil \\ ${ }^{3}$ Laboratory of Immunobiology and Serum Epidemiology, \\ Institute of Tropical Medicine, University of Sao Paulo, Sao Paulo, Brazil \\ ${ }^{4}$ Departament of Immunology, Institute of Biomedical Sciences, University of Sao Paulo, Sao Paulo, Brazil \\ ${ }^{5}$ Department of Veterinary Clinics, Faculty of Veterinary Medicine, Federal University of Parana, Palotina, Brazil \\ ${ }^{6}$ Departament of Clinical Sciences, \\ Faculty of Veterinary Medicine and Animal Sciences, University of Sao Paulo, Sao Paulo, Brazil
}

Received 2012-09-07, Revised 2012-09-22; Accepted 2012-10-18

\begin{abstract}
Mastitis is the most costly disease for dairy farmers and industry, which are mainly caused by the entry of bacteria to the teat canal. Shortly after the entry of the invading bacteria, the innate immunity recognizes the invading pathogen through pattern recognition receptors and initiates the inflammatory response necessary to eliminate the invading bacteria. This initial inflammatory response releases cytokines and chemoattractants for the rapid and massive influx of neutrophils from the blood to the site of infection which form the first line of cellular defense against bacteria This article reviewed the role of the most recent knowledge regarding the innate immunity in bovine mastitis focusing in the two major mastitis pathogens: Escherichia coli and Staphylococcus aureus the $S$. aureus appears to mostly circumvent the host immune response, as the Toll-Like Receptors (TLRs) signaling pathways. The Intramammary Infections (IMIs) by this bacteria result in a very moderate host response with minimal observable innate immune response, which are related to well-known ability to this pathogen to establish chronic IMI. Otherwise, E. coli elicits a strong and earlier response, mainly through TLR4, that is associated with the severity of the mastitis and the clinical manifestation commonly observed in dairy cows infected with this pathogen. Suboptimal and dysfunctional mammary defenses may contribute to the development of severe acute inflammation or chronic mastitis that adversely affects the milk production and quality. Thus, a better understanding of mastitis pathogen interaction to the host may be useful for future control of mastitis.
\end{abstract}

Keywords: Dairy Cows, Intramammary Infections, Mammary Gland, PAMPs, Toll-Like Receptors

\section{INTRODUCTION}

Mastitis is the most costly disease for dairy farmers and industry (Hujips et al., 2008; Hogeveen et al., 2011). Bovine mastitis is defined as an inflammatory condition of the mammary gland in response to injury, which serve to destroy and neutralize infectious agents and promote healing and the return to normal function. More than 130 microorganisms can cause mastitis, although this disease is usually caused by some groups of bacteria (Wellenberg et al., 2002; Hillerton and Berry, 2005). In the last few years, antimicrobial resistance has been growing concern worldwide. Thus, in an attempt to reduce the impact of mastitis and decrease the use of antimicrobials on dairy farms, there have been numerous efforts to try to exploit the immune capacity of the bovine mammary gland Corresponding Author: Fernando Nogueira de Souza, Departament of Preventive Veterinary Medicine, Veterinary School, Federal University of Minas Gerais, Belo Horizonte, Brazil 
to stimulate the animal's natural defense mechanisms. These facts can reduce the use of antimicrobials and also minimize the development of resistance of bacterial strains (Wellnitz and Bruckmaier, 2012).

The role of Toll-Like Receptors (TLRs) in innate and adaptive immunity has been subject of many good reviews (Medzhitov, 2001; Takeda et al., 2003; Akira and Takeda, 2004; Iwasaki and Medzhitov, 2004; Takeda and Akira, 2004; Hornung and Latz, 2010; Takeuchi and Akira, 2010; Kawai and Akira, 2011; Prince et al., 2011). Therefore, there is a need to summarize the role of these new concepts in bovine mastitis. In this review, we focus on the most recent knowledge about TLRs in bovine mastitis regarding their role in the major mastitis pathogens: Escherichia coli and Staphylococcus aureus.

\subsection{Innate Immunity}

Bovine mastitis is initiated by the entry of bacteria through the teat canal and soon after is characterized by an important inflammatory response. Shortly after entry of the invading pathogen, the resident leukocytes together with epithelial cells initiate the inflammatory response necessary to eliminate the invading bacteria (Paape et al., 2003; Rainard and Riollet, 2006; Aitken et al., 2011). These cells release chemoattractants for the rapid recruitment of polymorphonuclear neutrophil leukocytes to the site of infection and consequently the Somatic Cell Count (SCC) increases, which represents different cells types present in milk, including leukocytes and epithelial cells (Paape et al., 2003; Souza et al., 2012). The marked increase in milk SCC during infection is mainly due to influx of neutrophils from blood to the mammary gland, which neutrophils can represent over $90 \%$ of leukocyte population in milk from infected udder quarters in contrast to low numbers of this cell population in uninfected ones (Paape et al., 2003; Pyorala et al., 2003; Souza et al., 2012).

Neutrophils are essential for innate host defense against invading microorganisms and eliminate pathogens by a process known as phagocytosis. During phagocytosis, neutrophils produce reactive oxygen species, including superoxide, hydrogen peroxide and hypochlorous acid and release granule compounds into pathogen-containing vacuoles to kill the invading pathogen (Paape et al., 2003; Mehrzad et al., 2005; Rainard and Riollet, 2006; Prince et al., 2011). Thus, the rapid influx of neutrophils with high antimicrobial activity to the foci of infection is the main process that leads to the elimination of infection (Mehrzad et al., 2005). This importance was demonstrated by Mehrzad et al. (2005) who described that SCC in moderate cows increase faster that Colony Forming Units (CFU) of E. coli bacteria, whereas in severe cows the results were reversed.

Conversely, inflammation and tissue injury, as caused by the influx of neutrophils, can result in the release of endogenous TLRs ligands, known as DamageAssociated Molecular Patterns (DAMPs). DAMPs act in an autocrine manner, alerting the host of damage, but can also amplify inflammation leading to further tissue damage (Prince et al., 2011). In contrast, an apoptosis differentiation program facilitates the resolution of neutrophil-mediated inflammatio. It has been suggested that phagocytosis initiates molecular cascade of events that accelerates apoptosis of this leukocyte population. Thus, as neutrophils can accumulate rapidly at sites of infection and there is a concomitant potential to cause severe tissue destruction if they undergo necrosis lysis and release cytotoxic granule and reactive oxygen species onto host tissues. Thus, apoptosis can be viewed as the terminal stage of neutrophil-induced inflammation (Kobayashi et al., 2003).

Recognition of microbial pathogens is an essential element for initiation of innate immune responses such as inflammation and is mediated by germline-encoded Pattern-Recognition Receptors (PRRs) that recognize molecular structures that are broadly shared by pathogens, known as Pathogen-Associated Molecular Patterns (PAMPs). Upon PAMP recognition, PRRs initiate a serious of signaling programs that execute the first line of host defensive responses necessary for killing infectious microbes (Medzhitov, 2001; Takeda et al., 2003; Akira and Takeda, 2004; Iwasaki and Medzhitov, 2004; Takeda and Akira, 2004; Takeuchi and Akira, 2010; Kawai and Akira, 2011; Prince et al., 2011). TLRs were the first PRRs identified. They are also the best characterized PRRs and recognize a wide range of PAMPs. They are expressed either on the cell surface or associated with intracellular vesicles (Medzhitov, 2001; Takeda and Akira, 2004). To date, 10 functional TLRs have been identified in bovine (Menzies and Ingham, 2006). These 10 TLRs and Nucleotide-binding Oligomerization Domain (NOD) 1 and 2 was detected in tissue from alveolar, ductal, gland cistern and teat canal from infected and healthy quarters, with TLR 8 having the least expression in comparison to the other PRRs (Whelehan et al., 2011). Functional analysis of mammalian TLRs has revealed that they recognize specific patterns of microbial components that are conserved among pathogens (Takeda and Akira, 2004). Each TLR detect distinct PAMPs derived from bacteria, viruses, mycobacteria, fungi and parasites. For instance, these include lipoproteins (recognized by TLR1, TLR2 and TLR6), flagellin (TLR5), lipopolysaccharide (LPS) (TLR4) and a 6-base DNA motif consisting of an unmethylated $\mathrm{CpG}$ dinucleotide motifs (CpG DNA) that are rarely found in higher vertebrates (TLR9) (Table 1) (Medzhitov, 2001; Takeda et al., 2003; Akira and Takeda, 2004; Iwasaki and Medzhitov, 2004; Takeda and Akira, 2004; Takeuchi and Akira, 2010; Kawai and Akira, 2011). 
Table 1. Toll-like receptors and their ligands*

\begin{tabular}{lll}
\hline Receptor & Ligand & Origin of ligand \\
\hline TLR1 & Triacyl Lipopeptides & Bacteria and mycobacteria \\
TLR2 & Lipoprotein/Lipopeptides & Various pathogens \\
& Peptidoglycan & Gram-positive bacteria \\
& Lipoteichoic acid & Gram-positive bacteria \\
& Lipoarabinomannan & Mycobacteria \\
& Phenol-soluble modulin & Staphylococcus epidermitis \\
TLR3 & Zymosan & Fungi \\
TLR4 & Double-stranded RNA & Viruses \\
& Lypopolysaccharide & Gram-negative bacteria \\
TLR5 & Fusion protein & Respiratoty syncytial virus \\
TLR6 & Flagelin & Bacteria \\
& Diacil lipopeptides & Mycoplasma \\
TLR7 & Lipoteichoic acid & Gram-positive bacteria \\
TLR8 & Zymosan & Fungi \\
TLR9 & Single stranded RNA & Viruses \\
TLR10 & Single stranded RNA & Viruses \\
\hline Adapt & CpG-containing DNA & Bacteria and viruses
\end{tabular}

Adapted from Akira and Takeda (2004); N.D.: Not Determined; *Only ligands that can be related to mastitis pathogens was included

For instance for the role of TLRs in bovine mammary gland, it was found that LPS induced the expression of the chemokines MCP-1, MCP-2 and MCP-3 and slightly increase in CXCL8. Conversely, peptidoglycan combined with Lipotechoic Acid (LTA) induced the expression of MCP-1 and a slightly increase in MCP-3 expression. Indeed, no significant expression for any of the chemokines was observed when induced by $\mathrm{CpG}$ DNA (Mount et al., 2009).

Furthermore, it should note that the TLRs can act together with other molecules or other TLRs. For instance, TLR4 requires other molecules in addition to TLR4 to recognize LPS. LPS binds to the LPS-Binding Protein (LBP) present in serum and this LPS-LBP complex is subsequently recognized by CD14, which is expressed on monocytes/macrophages and neutrophils. Moreover, LPS stimulation is followed by the increased physical proximity between CD14 and TLR4 in the membrane, suggesting that CD14 and TLR4 may interact in LPS signaling. Indeed, the TLR2 act in cooperation at least with two other TLRs: TLR1 and TLR6. So, the formation of heterodimers between TRL2 and either TLR1 or TLR6 dictates the specificity of ligand recognition (Medzhitov, 2001; Takeda et al., 2003; Akira and Takeda, 2004; Iwasaki and Medzhitov, 2004; Takeda and Akira, 2004; Takeuchi and Akira, 2010; Kawai and Akira, 2011). Another factor that can influence the innate immune response in bovine is cell maturation, as demonstrated for the same monocytes subsets-monocytes, macrophages and dentritic cells, which have different responses to the same TLR agonist (Werling et al., 2004).
All TLR signal transduction pathways are known to activate NF- $\kappa$ B factors (Akira and Takeda, 2004). MyD88 (myeloid differentiation primary-response protein 88) dependent pathways are associated with early-phase NF- $\kappa \mathrm{B}$ response whereas as MyD88 independent pathways are associated with late-phase NF$\kappa \mathrm{B}$ response. These NF- $\kappa \mathrm{B}$ factors subsequently enter the nucleus and bind to target promoters. A wealth of proinflammatory regulated genes feature NF- $\kappa B$ attachment sites in their promoter region and transcription factor complex act as a main switch to orchestrate immune defense genes against bacterial infection, as production of several pro-inflammatory cytokines.

Thus, the innate immune system uses various PRRs that are expressed on the cell surface, in intracellular compartments, or secreted into the blood stream and tissue fluids. The principal functions of PRRs include: opsonization, activation of complement and coagulation cascade, phagocytosis, activation and induction of apoptosis (Medzhitov, 2001). For instance, TLR signaling pathway by bacteria regulated phagocytosis at multiple steps including internalization and phagossome maturation (Blander and Medzhitoz, 2004).

The importance of the innate immunity (TLR2, Tumor Necrosis Factor (TNF)- $\alpha$, interleukin (IL-) $1 \beta$, IL6 , IL-8 complement factor C3, lactoferrin and RANTES) was also demonstrated by the significantly elevated expression of these innate immune genes in lesssusceptible cattle when compared to high susceptibility group by detection of Quantitative Trait Loci (QTL) affecting mastitis (Griesbeck-Zilch et al., 2009). 


\subsection{Mastitis caused by Escherichia Coli}

E. coli is among the major mastitis pathogens responsible for clinical mastitis in dairy cows, but the infection are normally cleared by the immune system within a few days. Indeed, in last few decades, with the improvement of mastitis control programs, which leads to herds with low SCC, the clinical mastitis has become a major problem in many well-managed dairy herds that successfully controlled contagious pathogens (Green et al., 2004). Gram-negative bacteria, such as E. coli, are generally regarded as environmental pathogens, however contagious behavior of these pathogens has been proposed (Burvenich et al., 2003; Dogan et al., 2006; Suojala et al., 2011). With this in mind, it has been suggested that clinical bovine $E$. coli mastitis isolates differ from cowshed environmental $E$. coli isolates and may form a subset of environmental $E$. coli population. Mastitis isolates showed faster growth in the udder medium and can evade the host cellular innate immune response (Blum et al., 2008).

$E$. coli express a variety of virulence factors, but no coherence between the severity of disease and specific virulence factors could be defined (Wenz et al., 2006; Suojala et al., 2011; Schukken et al., 2011). The ability to grow in mammary secretions and to liberate LPS is crucial in the pathogenesis of $E$. coli mastitis. The faster bacterial numbers increase in the mammary gland, more LPS is present in the mammary gland and faster inflammatory response and clinical disease may occur (Mehrzad et al., 2008). Sensing the pathogen and initiating an immune response depends on the initial number of bacteria present at the start of the IMI. Increase the initial challenge dose of $E$. coli resulted in faster immune response in primiparous cows (Vangroenweghe et al., 2004; Schukken et al., 2011), which the extend of induced cytokines synthesis, such as TNF- $\alpha$ and IL-8, in mammary epithelial cells positively correlated with the concentration of E. coli particles (Guntler et al., 2010). Congruently, expression of IL-8 and Interferon (IFN)- $\gamma$ by milk somatic cells was increased in $E$. coli challenged mammary glands (Lee et al., 2003).

Buitenhuis et al. (2011) also described that in the early E. coli mastitis a large number of up-regulated transcripts were associated with immune response functions, mainly those involved in acute phase response, while the down-regulation transcripts were principally involved in fat metabolism, which is consistent with the milk fat content depression commonly observed during mastitis infection and later the up-regulated transcripts were associated with tissue healing processes and were independent of E. coli strain and dose and lactation stage and number. Another factor that should be considered is the linkage between lipid metabolism and inflammation, as the nuclear receptors known as Peroxisome Proliferator-Activated Receptors (PPARs) and Liver X Receptors (LXRs) that emerged as key regulators of lipid metabolism and inflammation (Lubick and Jutila, 2006; Bensinger and Tontonoz, 2008; Rios et al., 2008; Aitken et al., 2011; Moyes et al., $2010 \mathrm{a}$; 2012b), as has been demonstrated in mammary glands infected with Streptococcus uberis (Moyes et al., 2010a).

The innate immune system represents the first line of defense in the host response to infection and is poised to immediately recognize and respond to the earliest stages of infection. The inherent capability of the innate system to respond to a vast number of pathogens is mediated by its ability to recognize highly conserved motifs shared by diverse pathogens, commonly referred to as PAMPs. It has been shown that a prompt response of the mammary after $E$. coli entry into the lumen of the gland is required to control the infection, which means that early detection of bacteria are of prime of importance (Bannerman et al., 2004; Porcherie et al., 2012).

The incidence and severity of septic E. coli mastitis in dairy cattle is mainly dependent on cow factors. During the periparturient period, the non-specific or innate immunity of the cow is depressed, which makes cows more susceptible to Intramammary Infection (IMI) by environmental pathogens like $E$. coli, while cows in mid lactation cure spontaneously from such infections (Burvenich et al., 2003; Mehrzad et al., 2005). There is substancial evidence indicating that at these periods, the expected influx of neutrophils, which form the first cellular defense against infection (Paape et al., 2003), into the mammary gland is delayed during inflammation after IMI with E. coli (Mehrzad et al., 2005; Schepper et al., 2007). In fact, the perturbations in neutrophil functions during early lactation are accompanied by modulation of TLR4 pathway genes, as diapedesis and migration process (Stevens et al., 2011).

Furthermore, Mehrzad et al. (2005) when classified cows as moderate and severe responders according to clinical symptoms and milk production output, observed an inverse relationship between pre-infection milk neutrophils microbicidal activity and CFU E. coli bacteria in milk, where the moderate cows the preinfection milk and blood neutrophils microbicidal activity was about two fold higher than the severe cows.

Mammary epithelial cells challenged by $E$. coli bacteria must have the capacity to mountain a strong innate immune response in their own right and attract circulating immune effector cells such as neutrophils. The importance of these cells is demonstrated by their 
role in the production of cytokines (Riollet et al., 2000; Strandberg et al., 2005; Griesbeck-Zilch et al., 2008; Guntler et al., 2011; Porcherie et al., 2012). The upregulation of cytokine production is a key component of the host innate immune response to infection (Bannerman et al., 2004; Schukken et al., 2011).

Regarding bovine Mammary Epithelial Cells (bMEC), Porcherie et al. (2012) showed that these cells are key players in initiating neutrophil inflammation during $E$. coli mastitis, as for instance, by the production of the chemotractic factor CXCL8 (IL-8). So, recognition of several PAMPs at a time could contribute to the onset of an early response of the cow after infection by $E$. coli. These authors showed that a repertorie of potential bacterial agonists can be sensed by bMEC and udder during E. coli mastitis, as which both bMEC and udder can express domain receptors for NOD1, NOD2, TLR1, TLR2, TLR4 and TLR6, but not hardly TLR5 and can act synergistically. So, LPS upon activation of TLR4 present a central role in the pathogenesis of clinical mastitis caused by this pathogen (Gonen et al., 2007) in a dose-dependent manner (Baumert et al., 2009). The inflammation caused by LPS also leads to alteration in milk parameters, as lactose and chloride levels, in dose dependent manners which are likely caused by greater tight junction damage by higher LPS doses (Werner-Misof et al., 2007). These parameters are also used to evaluated the indicators of inflammation in bovine mastitis and consequently in their diagnosis (Pyorala et al., 2003).

Lazard et al. (2011) demonstrated that neutrophil recruitment to the milk spaces is mediated through TNF$\alpha$, which is produced by alveolar macrophages in response to LPS/TLR4 signaling and is dependent on IL8 and IL-1 $\beta$ signaling and regulated by iNOS-derived NO in a murine mastitis model. The ability to recruit cells into the mammary gland during the bacterial growth phase represent a crucial role since a $1 \mathrm{~h}$ delay in recruiting neutrophils can result in an 8-fold increase of E. coli (Hill, 1981). Both the MyD88 dependent and independent pathways in TLR4 signaling were activated in bMEC model (Ibeagha-Awemu et al., 2008). Despite the importance of LPS/TLR4 signaling pathway, Gonen et al. (2007) described that IMI of mice with $E$. coli $\mathrm{P} 4$ resulted in inflammation even in absence of LPS/TLR signaling. This inflammation response pointing out to additional factors beyond LPS and additional cells beyond alveolar macrophages play a role in the inflammatory response to E. coli. It has been suggested that in the absence of functional TLR4 the infecting E. coli P4 invaded epithelial cells with high efficiency, forming intracellular micro- colonies, since invasion of epithelial cells by E. coli is limited by alveolar macrophages using a process dependent on TLR4 signaling (Gonen et al., 2007; Elazar et al., 2010b; Schukken et al., 2011).

Infections caused by $E$. coli are more typically, but not exclusively, associated with fast and more dramatic immune response (Lee et al., 2003; Schukken et al., 2011). IMI with E. coli elicited systemic changes, including a febrile response and induction of acute-phase synthesis of LBP. In milk, this infection resulted in increased levels of insulin-like growth factor-1, IL-1 $\beta$, IFN- $\gamma, \quad$ IL-12, IL-8, TNF- $\alpha$, sCD14, LBP, the complement cleavage factor $\mathrm{C} 5 \mathrm{a}$, lactoferrin, lysozyme and lipid mediators, such as cyclooxygenase-2 and 5lipoxygenase (Riollet et al., 2000; Bannerman et al., 2004; Schmitz et al., 2004).

Petzl et al. (2008) reported that E. coli inoculation in the mammary gland strongly upregulated the expression of $\beta$-defensins, TLR2 and TLR4 in the pathogen inoculated udder quarters, as well as, in mammary lymph nodes. In constrast, $S$. aureus did not significantly regulate the expression of these genes during the first 24 $\mathrm{h}$ after pathogen inoculation. Only $84 \mathrm{~h}$ after inoculation, the expression of $\beta$-defensins, but not of TLRs was significantly upregulated $(<20$ fold $)$ in $S$. aureus inoculates mammary glands.

E. coli IMIs induce distinct local and systemic transcriptome responses in the mammary gland. The local response, only in infected quarters, mainly involved in immune response and inflammation, while the systemic reactions, in both infected and neighboring quarters, comprises antigen processing and presentation, cytokines, protein degradation and apoptosis. Enhanced expression of antimicrobial genes, acute phase genes and indicators of oxidative stress point out to an active defense reaction in infected and neighboring healthy quarters (Mitterhuemer et al., 2010).

In this concern, data support an important sentinel function for teats, as these tissues respond rapidly and intensively, with production of cytokines and antimicrobial peptides. For example, genomic analysis at $12 \mathrm{~h}$ post-infection with $E$. coli the inflammatory response was greatest in teat cistern and gland cistern. Only $24 \mathrm{~h}$ post-infection, the lobulo-alveolar region responds, at the time the inflammatory response was greatest of all regions (Rinaldi et al., 2010).

\subsection{Mastitis Caused by Staphylococcus Aureus}

$S$. aureus mastitis remains a worldwide problem for the dairy industry and producers and can cause both subclinical and clinical mastitis (Barkema et al., 2006), which severity and outcome of infection depend, in part, 
on strain-factors (Marechal et al., 2011) and cow factors (Barkema et al., 2006). The cure rate of antimicrobial treatments for this agent is low and, therefore, the disease has not been effectively eliminated and/or controlled in many herds (Barkema et al., 2006). Staphylococcal infections are characterized by an ability to colonize the mammary tissue and survival of the bacterial inside epithelial cells, macrophages and even neutrophils (Gresham et al., 2000; Hebert et al., 2000; Lowy, 2006).

It is commonly assumed that most IMI are result of cow-to-cow transmission, however other sources of $S$. aureus bacteria in the environment of dairy cow have been described. Presumably, contagious strain of $S$. aureus co-exists with a large collection of noncontagious strains (Zadoks et al., 2002). Haveri et al. (2007; 2008) compared bacterial genomics of strains from persistent infections and form transient infections and found that genetic elements such as clonal type and penicillin resistance were over-represented in $S$. aureus isolated from persistent IMI. This microorganism is characterized by dynamic fluctuations and cyclic bacterial shedding in milk, which leads to fluctuations in milk SCC that normally fluctuate depending on organism's number and viability (Schukken et al., 2011; Souza et al., 2012).

In contrast to $E$. coli mastitis, $S$. aureus mastitis is characterized by a more moderate and delayed SCC increase, due in part, to limited cytokine response (Bannerman et al., 2004). Congruently, Riollet et al. (2000) also described no detection of IL-1 $\beta$, TNF- $\alpha$, IL8 , bovine serum albumin, in milk whey from $S$. aureus infected animals. Indeed, the ability of milk to generate the complement cleavage product $\mathrm{C} 5 \mathrm{a}$ in whey samples after addition of zymosan through complement activation was evaluated and E. coli lead to a huge augment of C5a production (up to 100 -fold), in contrast to a much less production in whey milk from $S$. aureus infected animals. Rainard et al. (2008) also showed that LTA from $S$. aureus induced an increase in chemokine and IL$1 \beta$, but little TNF- $\alpha$ in the milk.

Although, $S$. aureus is regarded as a gram-positive bacteria, the expression of TLR2 were correlated with TLR4, indicating coordinating regulation of these two PRRs (Goldammer et al., 2004; Ibeagha-Awemu et al., 2008), although the expression of TLR9 was not increased in mastitis (Goldammer et al., 2004).

Cytokine gene expression in mammary epithelial cells induced by $S$. aureus infection was delayed and less than $5 \%$ of the cytokine expression observed in experiment of E. coli (Lee et al., 2003; Yang et al., 2008; Guntler et al., 2010). This impaired proinflammatory activation is paralleled by a complete lack of NF- $\mathrm{kB}$ activation in primary bovine mammary epithelial cells by $S$. aureus or LTA. In contrast to E. coli and LPS that activates strongly NF- $\mathrm{kB}$ in these cells. A large proportion of this activation is attributable to TLR-mediated signaling, since dual transdominant negative DN-MyD88-DN-TRIF factor blocks more than $80 \%$ of the pathogen-related NF- $\mathrm{KB}$ activation in primary bovine mammary epithelial cells. These facts may contribute to well-known ability of this bacterium to establish chronic intramammary infections (Yang et al., 2008; Guntler et al., 2011).

For example, the Interleukin (IL)-8 and TNF- $\alpha$ were not detected in milk from quarters experimentally infected with $S$. aureus (Riollet et al., 2000; Bannerman et al., 2004), although, the mRNA expression of TNF- $\alpha$ in mammary cells increases during infection (Alluwaimi et al., 2003). Expression of IL-8 by milk somatic cells was also increased in $S$. aureus challenged mammary glands, but in lower magnitude than $E$. coli challenged mammary glands. Although, the expression of IFN- $\gamma$ was not increased in milk somatic cells from $S$. aureus challenged quarters (Lee et al., 2003).

In vitro, mammary epithelial cells demonstrated greater mRNA expression of IL- $1 \beta$, IL- 8 and TNF- $\alpha$ $24 \mathrm{~h}$ after infection with $E$. coli than $S$. aureus (Lahouassa et al., 2007). Wellnitz et al. (2011) also found that infusion of $E$. coli LPS induced an increased TNF- $\alpha$ in milk from glands given LPS, but not by $S$. aureus LTA. The levels of lactate dehydrogenase, an enzyme released by degenerating cells, was greater in milk from glands instilled with LPS than with LTA. LPS was also a stronger induced of IL-8 and IL- $1 \beta$.

Conversely, the ability of to induce clinical or subclinical mastitis was dependent on the dose used. LTA proved to induce strongly the secretion of the chemokines CXCL1, CXCL2, CXCL3 and CXCL8, which induced neutrophils recruitment. The complement-derived chemoattractant $\mathrm{C} 5 \mathrm{a}$ was generated in milk only with the highest dose of LTA used. Furthermore, the pro-inflammatory cytokine IL-1 $\beta$ has been induced in milk, but there is few amount of TNF- $\alpha$ and no IFN- $\gamma$ (Rainard et al., 2008).

The Muramyl Peptide (MDP), an elementary constituent of the bacterial peptidoglycan, induce a prompt influx of neutrophils mediated by chemoattractants for these leukocytes (CXCL1, CXCL2, CXCL3, CXCL8 and C5a) and the highest concentrations of these chemoattractants were followed after challenge in combination with LTA, which signal transduction is mediated by TLR2, although they not 
contribute significantly to pro-inflammatory cytokines. Thus, TLR2 and NOD2, a major sensor for MDP, pathways could cooperate to trigger an innate immune response to $S$. aureus mastitis (Bougarn et al., 2010).

Induction of immune functions in mammary epithelial cells is accomplished via the activation of the relevant TLR and their downstream signaling pathways. Induction of these genes by $S$. aureus is reduced, due to, in part, impairment of MyD88 signaling, immediately downstream from trans-membrane TLR (e.g., TLR2, TLR4). S. aureus apparently prevents the formation of so-called Myddossome around TIR domain of the TLR forming the structural plataform for the attachment of further downstream acting factors (Motshwene et al., 2009; Lin et al., 2010; Schukken et al., 2011). As a consequence, $S$. aureus elicits an immune response in these cells dominantly by IL-6, while $E$. coli also activates IL-1 $\beta$ and TNF- $\alpha$ (Guntler et al., 2011; Schukken et al., 2011). The upregulation of IL-6 by both bacteria may be due to a MyD88 independent mechanism (Guntler et al., $2010 ; 2011)$, which as cited above is associated with latephase NF- $\kappa \mathrm{B}$ response.

It has also been suggested that $S$. aureus impaired $\mathrm{NF}-\kappa \mathrm{B}$ activation in mammary epithelial cells resulting in very low cytokine expression (Lara-Zarate et al., 2011). These authors reported that bovine prolactin stimulates $S$. aureus internalization in bovine mammary gland by regulating several innate immune elements, which is often modulated by NF- $\mathrm{BB}$. On the other hand, prolactin induced NF- $\kappa \mathrm{B}$ activation in bovine mammary epithelial cells; however, it was inhibited by $S$. aureus in presence of this hormone. When, these authors blocked $\mathrm{NF}-\kappa \mathrm{B}$ activation with acetylsalicylic acid, an inhibition of $S$. aureus internalization was found (48\%) in prolactin stimulated cells. The infection of bovine mammary epithelial cells with $S$. aureus induced inhibition of NF- $\kappa \mathrm{B}$ activation in the presence of prolactin that correlates with down regulation in prolactin-mediated TNF- $\alpha$ (27\%) and nitric oxide production in mammary epithelial cells.

Curiously, Griesbeck-Zilch et al. (2008) encountered differences in expression of TLR2 and TLR4 by mammary epithelial cells in $S$. aureus and $E$. coli infections only after $24 \mathrm{~h}$, when $S$. aureus-induced expression was significant lower. In contrast, after $1 \mathrm{~h} S$. aureus induced a significantly higher expression level of TNF- $\alpha$ and IL-1 $\beta$, but after 6 and $24 \mathrm{~h}$ the transcription activity in $E$. coli treated cells was higher. In contrast, $E$. coli induced a significant increase expression of IL-8 after $1 \mathrm{~h}$, but $S$. aureus caused no alteration in this chemokine. The Regulated upon Activation, Normal TCell Expressed and Secreted (RANTES) increased in $S$. aureus and E. coli treated bovine mammary epithelial cells after $1 \mathrm{~h}$, whereas after 6 and $24 \mathrm{~h}$ the expression was significantly higher in $E$. coli treated cells. Lactoferrin showed a deviating expression pattern to pathogen stimulation, in which at $1 \mathrm{~h} \mathrm{E}$. coli induced a higher mRNA expression, whereas the highest level was reached after $24 \mathrm{~h}$ of $S$. aureus stimulation. The complement factor 3 was the only factor that responded equally to both microorganisms.

Genini et al. (2011) described that mastitis induced a prominence of metabolic and stress signals in the early stage and of the immune response and lipid metabolism in the late stage, both mechanisms apparently modulated by few genes. Comparison of $E$. coli and $S$. aureus infections in cattle revealed that affected genes showing opposite regulation had the same altered biological functions and provided evidence that $E$. coli caused a stronger host response. The majority of genes with opposed regulation associated with immune response belong to antigen presentation, inflammatory response, cell-to-cell signaling and interaction network. Both cell death and lipid metabolism were among the most significant molecular functions altered in proteins of cows infected with either E. coli or $S$. aureus.

After $48 \mathrm{~h}$ post-challenged with $S$. aureus TLR1 was significantly expressed in ductal, gland cistern and teat canal, TLR3 showed a moderate increase in teat canal tissue, TLR6 and TLR7 presented a moderate increased in gland cistern tissue, TLR5 and TLR7 were also significantly increased in alveolar in alveolar tissue. Conversely, the genes encoding TLR4, NOD1 and NOD2 were significantly decreased in teat canal tissue, TLR6 in ductal tissue and TLR8 in gland cistern tissue. TLR2, TLR9 and TLR10 showed no differential expression across these four tissues regions. Of the regions examined, chemokine and effector molecule expression was most significantly stimulated in alveolar tissue, in particular the expression of serum amyloid A and haptoglobulin, two acute phase proteins and defensins- $\beta 4$ and 5 (Whelehan et al., 2011).

Thus, $S$. aureus appears to mostly circumvent the host immune response and IMI typically result in a very moderate host response with minimal observable innate immune response (Bannerman et al., 2004; Bannerman, 2009; Petzl et al., 2008; Schukken et al., 2011).

\subsection{Therapeutic Opportunities}

CD14 either in membrane or in soluble form (sCD14) is a high-affinity protein for the complex of bacterial LPS and LPS-LBP protein and thus interact with TLR4 in LPS signaling (Medzhitov, 2001; Takeda et al., 2003; Nemchinov et al., 2006). Cells lacking mCD14, such as 
endothelial and epithelial cells, utilize sCD14 present in serum and milk to aid in LPS recognition by TLR4 (Aitken et al., 2011). Binding of soluble form of CD14 to LPS, found in the outer of $E$. coli, enhances the innate immune responses, reduces the severity of mastitis and facilitates clearance and neutralization of LPS, thus preventing the development of endotoxic mastitis. Thus, Lee et al. (2003) found that the infusion of recombinant bovine sCD14 lead to an increase in SCC, due to more rapid recruitment of neutrophils that was accompanied by a faster clearance of bacteria, lower concentration of TNF- $\alpha$ and IL- 8 in milk and milder clinical symptoms. Congruently, Nemchinov et al. (2006) demonstrated that the recombinant bovine CD14 receptor produced in plants reduced the severity of $E$. coli mastitis, leading to enhancement of LPS-induced neutrophil recruitment, lower numbers of viable bacteria in milk resulting in absence of clinical symptoms.

Kauf et al. (2007) in attempt to heighten the inflammatory response during $S$. aureus intramammary infection infused LPS in quarters experimentally infected with $S$. aureus. They found an increase in SCC in quarters between 24 and $72 \mathrm{~h}$ post LPS-infusion, as well as, an increase in bovine serum albumin in milk, which reflect alterations in vascular permeability and are indicator of udder quarter inflammation, between 4-48 and $480 \mathrm{~h}$ post LPS-infusion. There was no detection of TNF- $\alpha$ in $S$. aureus-infected quarters administrated PBS at any time during the study. Conversely, infected quarters infused with LPS showed an increased TNF- $\alpha$ concentrations in milk between 4-8 $\mathrm{h}$ post LPS-infusion. Moreover, a trend toward a lower recovery of viable bacteria from LPS- versus PBS-infused quarters between 4-13 $\mathrm{h}$ post LPS-infusion was observed. Interestingly, this trend occurred in the inflammatory responses elicited by LPS. Subsequent in vitro inoculation of milk obtained from udder quarters infused with LPS or PBS demonstrated that the growth of $S$. aureus in milk from LPS-infused udder was significantly inhibited and an overall negative correlation existed between milk SCC and in vitro $S$. aureus growth in milk inoculated with $S$. aureus and incubated for 6 or $12 \mathrm{~h}$.

In a mastitis rat model, the infusion of CpG-DNA in mammary glands stimulated the secretion of IL-6 and TNF- $\alpha$ at different points, reduced viable $S$. aureus (Zhu et al., 2007a) and E. coli (Zhu et al., 2008) in mammary tissues, decreased the activity of NAGase, promoted the expression of TLR9 and induced more rapid infiltration of neutrophils to mammary tissue at initial stages of experimentally induced mastitis induced in rat model (Zhu et al., 2007a; 2008). In goats, Zhu et al. (2007b) demonstrated that the infusion of CpG-DNA in the mammary glands induced a decrease in viable $E$. coli, reduced bacteria counts in milk, promoted the expression of TLR9, stimulated the production of IL-6, attenuated the impact of inflammation mediators on cells and significantly shortened the inflammation course.

The retinoid, a group of derivates of vitamin A, exert various immunomodulatory actions. It has been demonstrated that the administration of retinoid acids protects rats against neutrophil-induced oxidative stress in acute experimental mastitis (Gu et al., 2009a; 2009b). A mechanism by which this protection is conferred is through TLR4. Gu et al. (2010) found that TLR4 gene expression reached its peak earlier in retinoid acidtreated rats and that retinoid acid decreased NF-kB DNA binding activity and the level of IL- $1 \beta$ protein expression in mammary gland. So, retinoid acid leads to attenuation of LPS-induced inflammation response by repression of TLR4/NF- $\kappa B$ signaling system. Another mechanism that can also be involved was demonstrated by Uematsu et al. (2008) who found that retinoid acids, in a dosedependent manner, regulated the differentiation of interleukin 17-producing $\mathrm{T}$ helper cells, which in turn mediated neutrophil response (Schukken et al., 2011).

Pheromonicin-SA (Ph-SA) is an engineered multidomain bactericidal peptide (Qiu et al., 2003) that has effect against $S$. aureus. Zhu et al. (2012) when exposed primary mammary epithelial cells to $\mathrm{Ph}-\mathrm{SA}$ found that this compound increases the expression of TLR2, TNF- $\alpha$, IL-1 $\beta$, IL- 8 and lactoferrin and later the expression of TLR4. Thus, Ph-SA may be value as an antimicrobial in promoting innate immune response by $S$. aureus aureus-infected bovine mammary epithelial cells, especially regarding the inhibition of innate immune response induced by $S$. aureus which leads to the chronification of the inflammatory response (Bannerman et al., 2004; Lahouassa et al., 2007; Yang et al., 2008; Motshwene et al., 2009; Guntler et al., 2010; Lin et al., 2010; Lara-Zarate et al., 2011; Schukken et al., 2011; Wellnitz et al., 2012).

TLR signaling induces 25-hydroxyvitamin D3 $1 \alpha-$ hydrolase expression in macrophages. The 25hydroxyvitamin $\mathrm{D}_{3} 1 \alpha$-hydrolase is the primary enzyme that converts 25-hydroxyvitamin $\mathrm{D}_{3}$ to 1,25dihydroxyvitamin $\mathrm{D}_{3}$, the active vitamin $\mathrm{D}_{3}$ metabolite. It was shown that the expression 25-hydroxyvitamin D3 $1 \alpha$-hydrolase was significantly increased in tissue and cells from of infected mammary glands and was predominantly expressed in $\mathrm{CD}_{1} 4^{+}$cells (Nelson et al., 2010), which is expressed in both neutrophils and macrophages in milk (Paape et al., 1996). Thus, regarding the importance of innate immunity for mammary gland health (Paape et al., 2003; Rainard and Riollet, 2006; Elazar et al., 2010a; 2010b), efforts to find 
optimal range of 1 , 25-dihydroxyvitamin $\mathrm{D}_{3}$ concentrations for proper immune function in cattle has implications for bovine health.

\section{CONCLUSION}

The innate immunity is crucial to maintain mammary gland healthy which is mediated through recognition of Pattern Recognition Receptors (PRRs). The PRRs recognized specific patterns of microbial components that are conserved among pathogens known as PathogenAssociated Molecular Patterns (PAMPs). The interaction of PRRs and PAMPs mediated the inflammatory response characterized by each mastitis-causing pathogen that can contribute to the development of severe acute inflammation or chronic mastitis.

\section{ACKNOWLEDGEMENT}

The researchers are grateful to Conselho Nacional de Desenvolvimento Científico e Tecnológico (project $\mathrm{n}^{\circ}$ 480102/2011-2), Fundação de Amparo à Pesquisa do Estado de São Paulo and Núcleo de Apoio à Pesquisa em Vacinas from University of São Paulo for financial support.

\section{REFERENCES}

Aitken, S.L., C.M. Corl and L.M. Sordillo, 2011. Immunopathology of mastitis: Insights into disease recognition and resolution. J. Mammary Gland Biol. Neoplasia, 16: 291-304. PMID: 21938490

Akira, S. and K. Takeda, 2004. Toll-like receptor signalling. Nature Rev. Immunol., 4: 499-511. DOI: 10.1038/nri1391

Alluwaimi, A.W., C.M. Leutenegger, T.B. Farver, P.V. Rossito and W.L. Smith et al., 2003. The cytokine markers in Staphylococcus aureus mastitis of bovine mammary gland. J. Vet. Med., Series B: Infect. Dis. Vet. Public Health, 50: 105-111. PMID: 12667186

Bannerman, D.D., 2009. Pathogen-dependent induction of cytokines and other soluble inflammatory mediators during intramammary infection of dairy cows. J. Anim. Sci., 87: 10-25. PMID: 18708595

Bannerman, D.D., M.J. Paape, J.W. Lee, X. Zhao and J.C. Hope et al., 2004. Escherichia coli and Staphylococcus aureus elicit differential innate immune responses following intramammary infection. Clin. Diagnostic Laboratory Immunol., 11: 463-472. DOI: 10.1128/CDLI.11.3.463472.2004
Barkema, H.W., Y.H. Schukken and R.N. Zadoks, 2006. Invited review: The role of cow, pathogen and treatment regimen in the therapeutic success of bovine Staphylococcus aureus mastitis. J. Dairy Sci., 89: 1877-1895. PMID: 16702252

Baumert, A., R.M. Bruckmaier and O. Wellnitz, 2009. Dose dependant SCC changes after intramammary lipopolysaccharide challenge. Milk Sci. Int., 64: 119-121.

Bensinger, S.J. and P. Tontonoz, 2008. Integration of metabolism and inflammation by lipid-activated nuclear receptors. Nature, 454: 47-477. DOI: 10.1038/nature07202

Blander, J.M. and R. Medzhitoz, 2004. Regulation of phagosome maturation by signals from toll-like receptors. Science, 304: 1014-1018.

Blum, S., E.D. Heller, O. Krifucks, S. Sela and and S.O. Hammer-Muntz et al., 2008. Identification of a bovine mastitis Escherichia coli subset. Vet. Microbiol., 132: 135-148. PMID: 18571344

Bougarn, S., P. Cunha, A. Harmache, A. Fromageau and F.B. Gilbert et al., 2010. Muramyl dipeptide synergizes with Staphylococcus aureus lipoteichoic acid to recruit neutrophils in the mammary gland and to stimulate mammary epithelial cells. Clin. Vaccine Immunol., 17: 1797-1809. PMID: 20826612

Buitenhuis, B., C.M. Rontved, S. M Edwards, K.L. Ingvartsen and P. Sorensen, 2011. In depth analysis of genes and pathways of the mammary gland involved in the pathogenesis of bovine Escherichia coli-mastitis. BMC Genomics, 12: 130-130. DOI: 10.1186/1471-2164-12-130

Burvenich, C., V. Van Merris, J. Mehrzad, A. Diez-Fraile and L. Duchateau, 2003. Severity of $E$.coli mastitis is mainly determined by cow factors. Vet. Res., 34: 521564. PMID: 14556694

Dogan, B., S. Klaessig, M. Rishniw, R.A. Almeida and S.P. Oliver et al., 2006. Adherent and invasive Escherichia coli are associated with persistent bovine mastitis. Vet. Microbiol., 116: 270-281. PMID: 16787715

Elazar, S., E. Gone, A. Livneh-Kol, I. Rosenshine and N.Y. Sphpigel, 2010a. Neutrophil recruitment in endotoxin-induced murine mastitis is strictly dependent on mammary alveolar macrophages. Vet. Res., 41: 10-10. PMID: 19828114

Elazar, S., E. Gone, A. Livneh-Kol, I. Rosenshine and N.Y. Sphpigel, 2010b. Essential role of neutrophils but not mammary alveolar macrophages in a murine model of acute Escherichia coli mastitis. Vet. Res., 41: 53-53. PMID: 20416261 
Genini, S., B. Badaoui, G. Sclep, S.C. Bishop, D. Waddington and M.H.P.V. Laan et al., 2011. Strengthening insights into host responses to mastitis infection in ruminants by combining heterogeneous microarray data sources. BMC Genomics, 12: 225-225. PMID: 21569310

Goldammer, T., H. Zerbe, A. Molenaar, H.J. Schuberth, R.M. Brunner and S.R. Kata et al., 2004. Mastitis increases mammary mRNA abundance of $\beta$-defensin 5, Toll-Like Receptor 2 (TLR2) and TLR4 but not TLR9 in cattle. Clin. Diagnostic Laboratory Immunol., 11: 174-185. DOI: 10.1128/CDLI.11.1.174-185.2004

Gonen, E., A. Vallon-Eberhard, S. Elazar, A. Harmelln, O. Brenner and I. Rosenshine et al., 2007. Toll-like receptor 4 is needed to restrict the invasion of Escherichia coli P4 into mammary gland epithelial cells in a murine model of acute mastitis. Cellular Microbiol., 9: 2826-2838. PMID: 17608742

Green, M.J., L.E. Green, Y.H. Shukken, A.J. Bradley and E.J. Peeler et al., 2004. Somatic cell count distributions during lactation predict clinical mastitis. J. Dairy Sci., 87: 1256-1264. PMID: 15290974

Gresham, H.D., J.H. Lowrance, T.E. Caver, B.S. Wilson and A.L. Cheung et al., 2000. Survival of Staphylococcus aureus inside neutrophils contributes to infection. J. Immunol., 164: 37133722. PMID: 10725730

Griesbeck-Zilch, B., H.H.D. Meyer, C. Kuhn, M. Schwein and O. Wellnitz, 2008. Staphylococcus aureus and Escherichia coli cause deviating expression profiles of cytokines and lactoferrina messenger ribonucleic acid in mammary epithelial cells. J. Dairy Sci., 91: 2215-2224. PMID: 18487644

Griesbeck-Zilch, B., M. Osman, C. Kuhn, M. Schwerin and R.H. Bruckmaier et al., 2009. Analysis of key molecules of the innate immune system in mammary epithelial cells isolated from marker-assisted and conventionally selected cattle. J. Dairy Sci., 82: 4621-4633. PMID: 19700725

Gu, B., J. Miao, Y. Fa, J. Lu and S. Zou, 2010. Retinoic acid attenuates lipopolysaccharide-induced inflammatory responses by supressing TLR4/NF- $\mathrm{BB}$ expression in rat mammary tissue. Int. Pharmacol., 10: 799-805. PMID: 20438866

Gu, B.B., J.F. Miao, Y.M. Zhu, Y. Deng and S.X. Zou, 2009a. Protective effect of retinoid against endotoxin-induced mastitis in rats. Inflamm. Res., 58: 81-88. PMID: 19184358

Gu, B.B., Y.M. Zhu, W. Zhu, J.F. Miao and Y. Deng et al., 2009 b. Retinoid protects rats against neutrophilinduced oxidative stress in acute experimental mastitis. Int. Immunopharmacol., 9: 223-229. PMID: 19070684
Guntler, J., K. Esch, N. Poschadel, W. Petzl and H. Zerbe et al., 2011. Comparative kinetics of Escherichia coli- and Staphylococcus aureusspecific activation of key immune pathways in mammary epithelial cells demonstrates that $S$. aureus elicits a delayed response dominated by Interleukin-6 (IL-6) but not by IL-1A or tumor necrosis factor alpha. Infect. Immun., 79: 695-707. DOI: 10.1128/IAI.01071-10

Guntler, J., S. Liu, K. Esch, H.J. Schuberth and H.M. Seyfert, 2010. Stimulated expression of TNF-[alpha] and IL-8, but not of lingual antimicrobial peptide reflects the concentration of pathogens contacting bovine mammary epithelial cells. Vet. Immunol. Immunopathol., 135: 152-157. PMID: 19963279

Haveri, M., A. Roslof, L. Rantala and S. Pyorala, 2007. Virulence genes of bovine Staphylococcus aureus from persistent and nonpersistent intramammary infections with different clinical characteristics. J. Applied Microbiol., 103: 993-1000. PMID: 17897203

Haveri, M., M. Hovinen, A. Roslof and S. Pyorala, 2008. Molecular types and genetic profiles of Staphylococcus aureus strains isolated from bovine intramammary infections and extramammary sites. J. Clin. Microbiol., 46: 3778-3735. PMID: 17897203

Hebert, A., K. Sayasith, S. Senechal, P. Dubreuil and J. Lagace, 2000. Demonstration of intracellular Staphylococcus aureus in bovine mastitis alveolar cells and macrophages isolated from naturally infected cow milk. FEMS Microbiol. Lett., 193: 5762. PMID: 11094279

Hill, A.W., 1981. Factors influencing the outcome of Escherichia coli mastitis in the dairy cow. Res. Vet. Sci., 31: 107-112. PMID: 7031811

Hillerton, J.E. and E.A. Berry, 2005. Treating mastitis in the cow-a tradition or archaism. J. Applied Microbiol., 98: 1250-1255. PMID: 15916638

Hogeveen, H., K. Hujips and T.J. Lam, 2011. Economic aspects of mastitis: New developments. N Z Vet. J., 59: 16-23. PMID: 21328153

Hornung, V. and E. Latz, 2010. Intracellular DNA recognition. Nat. Rev. Immunol., 10: 123-130. PMID: 20098460

Hujips, K., T.J. Lam and H. Hogeveen, 2008. Costs of mastitis: Facts and perception. J. Dairy Res., 75: 113-120. PMID: 18226298

Ibeagha-Awemu, E.M., J.W. Lee, A.E. Ibeagha, D.D. Bannerman and M.J. Paape et al., 2008. Bacterial lipopolysaccharide induces increased expression of Toll-Like Receptor (TLR) 4 and downstream TLR signaling molecules in bovine mammary epithelial cells. Vet. Res., 39: 11-11. PMID: 18096120 
Iwasaki, A. and R. Medzhitov, 2004. Toll-like receptors and control of adaptive immune responses. Nature Rev. Immunol., 5: 987-995. PMID: 11973138

Kauf, A.C.W., B.T. Vinyard and D.D. Bannerman, 2007. Effect of intramammary infusion of bacterial lipopolysaccharideon experimentally induced Staphylococcus aureus intramammary infection. Res. Vet. Sci., 82: 38-46. PMID: 16887158

Kawai, T. and S. Akira, 2011. Toll-like receptors and their crosstalk with other innate receptors in infection and immunity. Immunity, 34: 637-650. DOI: 10.1016/j.immuni.2011.05.006

Kobayashi, S.D., J.M. Voyich and F.R. DeLeo, 2003. Regulation of the neutrophil-mediated inflammatory response to infection. Microbes Infection, 5: 13371344. DOI: 10.1016/j.micinf.2003.09.013

Lahouassa, H., E. Moussay, P. Rainard and C. Riollet, 2007. Differential cytokine and chemokine responses of bovine mammary epithelial cells to Staphylococcus aureus and Escherichia coli. Cytokine, 38: 12-21. PMID: 17532224

Lara-Zarate, L., J.E. Lopez-Meza and A. Ochoa-Zarzosa, 2011. Staphylococcus aureus inhibits nuclear factor kappa $\mathrm{B}$ activation mediated by prolactin in bovine mammary epithelial cells. Microbial. Pathogenesis, 51: 313-318. DOI: 10.1016/j.micpath.2011.07.010

Lazard, D.S., A.L. Giraud, E. Truy and H.J. Lee, 2011. Evolution of non-speech sound memory in postlingual deafness: Implications for cochlear implant rehabilitation. Neuropsychologia, 49: 24752482.

DOI:

10.1016/j.neuropsychologia.2011.04.025

Lee, J.W., M.J. Paape, T.H. Elsasser and X. Zhao, 2003. Recombinant soluble cd14 reduces severity of intramammary infection by escherichia coli. Infect. Immun., 72: 4034-4039.

Lin, S.C., Y.C. Lo and H. Wu, 2010. Helical assembly in the MyD88-IRAK4-IRAK2 complex in TLR/IL-1R signalling. Nature, 465: 885-890. DOI: 10.1038/nature09121

Lowy, F.D., 2006. Is Staphylococcus aureus an intracellular pathogen. Trends Microbiol., 8: 341343. PMID: 10920387

Lubick, K. and M.A. Jutila, 2006. LTA recognition by bovine $\gamma \delta$ T cells involves CD36. J. Leukocyte Biol., 79: 1278-1270. DOI: 10.1189/jlb.1005616

Marechal, C.L., N. Seyffert, J. Jardin, D. Hernandez and G. Jan et al., 2011. Molecular basis of virulence in Staphylococcus aureus mastitis. Plos One, 6: e27354-e27354. PMID: 22096559
Medzhitov, R., 2001. Toll-like receptors and innate immunity. Nature Rev. Immunol., 1: 135-145. PMID: 11905821

Mehrzad, J., D. Janssen, L. Duchateau and C. Burvenich, 2008. Increase in Escherichia coli inoculums dose accelerates $\mathrm{CD}^{+}$T-cell trafficking in primiparous bovine mammary gland. J. Dairy Sci., 91: 193-201. PMID: 18096940

Mehrzad, J., L. Duchateau and C. Burvenich, 2005. High milk neutrophil chemiluminescence limits the severity of bovine coliform mastitis. Vet. Res., 36: 101-116. PMID: 15610727

Menzies, M. and A. Ingham, 2006. Identification and expression of Toll-like receptors 1-10 in selected bovine and ovine tissues. Vet. Immunol. Immunopathol., 109: 23-30. PMID: 16095720

Mitterhuemer, S., W. Petzl, S. Krebs, D. Mehne and A. Klanner et al., 2010. Escherichia coli infection induces distinct local and systemic transcriptome responses in the mammary gland. BMC Genomics, 11: 138-138. DOI: 10.1186/1471-2164-11-138

Motshwene, P.G., M.C. Moncrieffe, J.G. Grossman, C. Kao and M. Ayaluru et al., 2009. An oligomeric signaling plataform formed by the toll-like receptor signal transducers MyD88 and IRAK-4. J. Biol. Chem., 284: 25404-25411. PMID: 19592493

Mount, J.A., N.A. Karrow, J.L. Casweel, H.J. Boermans and K.E. Leslie, 2009. Assessment of bovine mammary chemokine gene expression in response to lipopolysaccharide, lipotechoic acid + peptidoglycan and $\mathrm{CpG}$ oligodeoxynucleotide 2135. Canadian J. Vet. Res., 73: 49-57. PMID: 19337396

Moyes, K.M., J.K. Drackley, D.E. Morin and J.J. Loor, 2010b. Greater expression of TLR2, TLR4 and IL-6 due to negative energy balance is associated with lower expression of HLA-DRA and HLA-A in bovine blood neutrophils after intramammary mastitis challenge. Functional Integr. Genomics, 10: 53-61. PMID: 20072847

Moyes, K.M., J.K. Drackley, D.E. Morin, M. Bionaz and S.L. Rodrigues-Zas et al., 2010a. Gene network and pathway analysis of bovine mammary tissue challenged with Streptococcus uberis reveals induction of cell proliferation and inhibition of PPAR $\gamma$ signaling as potential mechanism for the negative relationship between immune response and lipid metabolism. BMC Genomics, 10: 542. PMID: 19925655

Nelson, C.D., T.A. Reinhardt, D.C. Beitz and J.D. Lippolis, 2010. In vivo activation of the intracrine vitamin D pathway in innate immune cells and mammary tissues during bacterial infection. Plos One, 5: 11e15469-e15469. PMID: 21124742 
Nemchinov, L.G., M.J. Paape, E.J. Shon, D.D. Bannerman and D.S. Zarlenga et al., 2006. Bovine CD14 receptor produced in plants reduces severity of intramammary bacterial infection. FASEB J., 21: 1345-1351. PMID: 16816109

Paape, M.J., D.D. Bannerman, X. Zhao and J.L. Lee, 2003. The bovine neutrophil: Structure and function. Vet. Res., 34: 597-627. PMID: 14556697

Paape, M.J., E.M. Liluis, P.A. Wiitanen, M.P. Kontio and R.H. Miller, 1996. Intramammary defense against infections induced by Escherichia coli in cows. Am. J. Vet. Res., 57: 477-482. PMID: 8712510

Petzl, W., H. Zerbe, J. Guntler, W. Yang and H.M. Seyfert et al., 2008. Escherichia coli, but not Staphylococcus aureus triggers an early increased expression of factors contributing to the innate defense in the udder of the cow. Vet. Res., 39: 1818. PMID: 18258172

Porcherie, A., P. Cunha, A. Trotereau, P. Roussel and F.B. Gilbert et al., 2012. Repertorie of Escherichia coli agonists sensed by innate immunity receptors of the bovine udder and mammary epithelial cells. Vet. Res., 43: 12-12. PMID: 22330199

Prince, L.R., M.K. Whyte, I. Sabroe and L.C. Parker, 2011. The role of TLRs in neutrophil activation. Curr. Opn. Pharmacol., 11: 397-403. PMID: 21741310

Pyorala, S., 2003. Indicators of inflammation in the diagnosis of mastitis. Vet. Res., 34: 565-578. DOI: 10.1051/vetres:2003026

Qiu, X.Q., H. Wang, X.F. Lu, J. Zhang and S.F. Li et al., 2003. An engineered multidomain bactericidal peptide as a model for targeted antibiotics against specific bacteria. Nat. Biotechnol., 21: 1480-1485. PMID: 14625561

Rainard, P. and C. Riollet, 2006. Innate immunity of the bovine mammary gland. Vet. Res., 37: 369-400. DOI: $10.1051 /$ vetres:2006007

Rainard, P., A. Fromageau, P. Cunha and F.B. Gilbert, 2008. Staphylococcus aureus lipoteichoic acid triggers inflammation in the lactating bovine mammary gland. Vet. Res., 39: 52. PMID: 18593548

Rinaldi, M., R.W. Li, D.D. Bannerman, K.M. Daniels and C. Evock-Clover et al., 2010. A sentinel function for teat tissues in dairy cows: Dominant innate immune response elements define early response to $E$. coli mastitis. Functional Integr. Genomics, 10: 21-38. PMID: 19727872
Riollet, C., P. Rainard and B. Poutrel, 2000. Kinetics of cells and cytokines during immune-mediated inflammation in the mammary gland of cows systemically immunized with Staphylococcus aureus alpha-toxin. J. Eur. Histamine Res., Soci., 49: 486-96.

Rios, F.J.O., S. Jancar, I.B. Melo, D.F.J. Ketelhuth and M. Gidlund, 2008. Role of PPAR-gamma in the modulation of CD36 and FcgammaRII induced by LDL with low and high degrees of oxidation during differentiation of the monocytic THP-1 cell line. Cellular Physiol. Biochem., 28: 549-565. PMID: 19088437

Schepper, S.D., A.D. Ketelaere, D.D. Bannerman, M.J. Paape and L. Peelman et al., 2007. The TollLike Receptor-4 (TLR-4) pathway and its possible role in the pathogenesis of Escherichia coli mastitis in dairy cattle. Vet. Res., 39: 05. PMID: 18073092

Schmitz, S., M.W. Pfaffl, H.H.D. Meyer and R.M. Bruckmaier, 2004. Short-term changes of mRNA expression of various inflammatory factors and milk proteins in mammary tissue during LPSinduced mastitis. Domestic Anim. Endocrinol., 26: 111-126. PMID: 14757184

Schukken, Y.H., J. Gunther, J. Fitzpatrick, M.C. Fontaine and L. Goetze et al., 2011. Host-response patterns of intramammary infections in dairy cows. Vet. Immunol. Immunopathol., 144: 270-289. PMID: 21955443

Souza, F.N., M.G. Blagitz, C.F.A.M. Penna, A.M.M.P.D. Libera and M.B. Heinemann et al., 2012. Somatic cell count in small ruminants: Friend or foe? Small Ruminant Res., 107: 65-75. DOI: 10.1016/j.smallrumres.2012.04.005

Stevens, M.G.H., L.J. Peelman, B. De Spiegeleer and A. Pezeshki et al., 2011. Differential gene expression of the toll-like receptor-4 cascade and neutrophil function in early-and mid-lactating dairy cows. J. Dairy Sci., 94: 1277-1288. PMID: 21338793

Strandberg, Y., C. Gray, T.Vuocolo, L. Donaldson and M. Broadway et al., 2005. Lipopolysaccharide and lipoteichoic acid induce different innate immune responses in bovine mammary epithelial cells. Cytokine, 31: 72-86. DOI: 10.1016/j.cyto.2005.02.010

Suojala, L., T. Pohjanvirta, H. Simojoki, A.L. Myllyniemi and A. Pitkala et al., 2011. Phylogeny, virulence factors and antimicrobial susceptibility of Escherichia coli isolated in clinical bovine mastitis. Vet. Microbiol., 147: 383-388. PMID: 20729012

Takeda, K. and S. Akira, 2004. TLR signaling pathway. Seminars Immunol., 16: 3-9. PMID: 14751757 
Takeda, K., T. Kaisho and S. Akira, 2003. Toll-like receptors. Annu. Rev. Immunol., 21: 335-376. PMID: 12524386

Takeuchi, O. and S. Akira, 2010. Pattern recognition receptors and inflammation. Cell, 140: 805-820. DOI: $10.1016 /$ j.cell.2010.01.022

Uematsu, S., K. Fujimoto, M.H. Jang, B.G. Yang and Y.J. Jung et al., 2008. Regulation of humoral and cellular gut immunity by lamina propria dendritic cells expressing toll-like receptor 5. Nat. Immunol., 9: 769-776. PMID: 18516037

Vangroenweghe, F., P. Rainard, M.J. Paape, L. Duchateau and C. Burvenich, 2004. Increase of Escherichia coli inoculums dosed induces faster innate immune response in primiparous cows. J. Dairy Sci., 87: 41324144. PMID: 15545375

Wellenberg, G.J., W.H.M. Van Der Poela and J.T.V. Oirschot, 2002. Viral infections and bovine mastitis: A review. Vet. Microbiol., 88: 27-45. PMID: 12119136

Wellnitz, O. and R.M. Bruckmaier, 2012. The innate immune response of the bovine mammary gland to bacterial infection. Vet. J., 192: 148-152. PMID: 22498784

Wellnitz, O., E.T. Arnold and R.M. Bruckmaier, 2011. Lipopolysaccharide and lipoteichoic acid induce different immune responses in bovine mammary gland. J. Dairy Sci., 94: 5405-5412. PMID: 22032363

Wenz, J.R., G.M. Barrington, F.B. Garry, R.P. Ellis and R.J. Magnuson, 2006. Escherichia coli isolates' serotypes, genotypes and virulence genes and clinical coliform mastitis severity. J. Dairy Sci., 89: PMID: 16899673

Werling, D., J.C. Hoep, C.J. Howard and T.W. Jungi, 2004. Differential production of cytokines, reactive oxygen and nitrogen by bovine macrophages and dendritic cells stimulated with Toll-like receptor agonists. Immunology, 111: 41-52. PMID: 14678198

Werner-Misof, C., J. Macuhoval, V. Tancin and R.M. Bruckmaier, 2007. Dose dependent changes in inflammatory parameters in the milk of dairy cows after intramammary infusion of lipopolysaccharide. Vet. Med., 52: 95-102
Whelehan, C.J., K.G. Meade, P.D. Eckersall, F.J. Young and C. O'Farrelly, 2011. Experimantal Staphylococcus aureus infection of the mammary gland induced region-specific changes in innate gene expression. Vet. Immunol. Immunopathol., 140: 181-189. PMID: 21292330

Yang, W., H. Zerbe, W. Petzl, R.M. Brunner and J. Guntler et al., 2008. Bovine TLR2 and TLR4 properly transduce signals from Staphylococcus aureus and $E$. coli, but $S$. aureus fails to both activate NF-kappaB in mammary epithelial cells and to quickly induce TNFalpha and interleukin-8 (CXCL8) expression in the udder. Mol. Immunol., 45: 1385-1397. DOI: 10.1016/j.molimm.2007.09.004

Zadoks, R.N., V. Leeuwen, D. Kreft, L.K. Fox and H.W. Barkema et al., 2002. Comparison of staphylococcus aureus isolates from bovine and human skin, milking equipment and bovine milk by phage typing, pulsed-field gel electrophoresis and binary typing. J. Clin. Microbiol., 40: 38943902. DOI: 10.1128/JCM.40.11.3894-3902.2002

Zhu, Y., H. Fan, J. Miao and S. Zou, 2008. Protective effect of CpG-DNA against mastitis induced by Escherichia coli infection in a rat model. Vet. J., 175: 369-378. PMID: 17408997

Zhu, Y.H., P.Q. Liu, X.G. Weng, Z.Y. Zhuge and R. Zhang et al., 2012. Pheromonicin-SA affects mRNA expression of toll-like receptors, cytokines and lactoferrin of Staphylococcus aureus-infected bovine mammary epithelial cells. J. Dairy Sci., 95: 759-764. PMID: 22281341

Zhu, Y.M., J.F. Miao, H.J. Fan, S.X. Zou and W.H. Chen, 2007a. Protective effect of CpG-DNA against mastitis induced by Staphylococcus aureus infection in a rat model. Int. Pharmacol., 7: 435-443. PMID: 17321466

Zhu, Y.M., J.F. Miao, Y.S. Zhang, Z. Li and S.X. Zou et al., 2007b. CpG-ODN enhamces mammary gland defense during mastitis induced by Escherichia coli in goats. Vet. Immunol. Immunopathol., 168: 176-176. PMID: 17869348 